\title{
Spontaneous Acute Subdural Hematoma as an Initial Presentation of Chronic Myeloid Leukemia
}

\author{
Ankur Jain $^{1} \cdot$ Pooja Prasad $^{1} \cdot$ Sumita Chaudhry $^{1} \cdot$ DK Gupta $^{1} \cdot$ Sumita Saluja $^{1}$
}

Received: 22 February 2019/Accepted: 11 March 2019/Published online: 22 March 2019

(C) Indian Society of Hematology and Blood Transfusion 2019

\section{Dear Editor,}

Chronic myeloid leukemia (CML) is a myeloproliferative disorder defined by the characteristic clonal alteration, Philadelphia chromosome. About $21 \%$ patients of CML present with bleeding symptoms. Purpura, menorrhagia, and retinal hemorrhage are the commonest manifestations [1]. Life threatening major hemorrhage at presentation is unusual.

A 68-year-old man presented in the emergency department of our hospital with sudden onset unconsciousness. On examination, he was drowsy and his vitals were: blood pressure-110/60 $\mathrm{mm} \mathrm{hg}$, pulse-62/min (regular), and respiratory rate- $16 / \mathrm{min}$. Neurological exam revealed bilateral extensor planter reflexes. Fundoscopy showed bilateral retinal hemorrhage. Rest of the systemic exam was unremarkable, except for a palpable liver $(4 \mathrm{~cm})$. Non-contrast CT scan of the head revealed a large subdural hematoma (SDH) causing midline shift. Complete blood counts were: hemoglobin-120 g/l, white cell count-114 $\times 10^{9} / 1$, and platelets-482 $\times 10^{9} / 1$. Peripheral smear showed marked leukocytosis, and a left-shifted myelogram. Serum biochemistry was normal, except for an elevated lactate dehydrogenase-550 U/L $(<250 \mathrm{U} / \mathrm{L})$. He underwent an emergency burr-hole evacuation of SDH. His sensorium improved after the procedure, and a hematology consultation was sought. Bone marrow examination suggested CML in chronic phase (CML-CP), and cytogenetic analysis of the marrow aspirate revealed Philadelphia chromosome. $\mathrm{Bcr}_{\mathrm{abl}}{ }^{210} \mathrm{mRNA}$ transcript was detected in the peripheral

\section{Sumita Saluja}

drssaluja@gmail.com

1 Department of Haematology, Vardhman Mahavir Medical College and Safdarjung Hospital, Delhi 110029, India blood by RT-PCR. His coagulation profile was: prothrombin time (PT)-13 s (control-13 s), activated partial thromboplastin time (APTT)-34 s (control-34 s), thrombin time (TT)-18 s (control-18 s), Factor VIII activity-100\% (50-150\%), Factor IX activity-92\% (50-150\%), von Willebrand factor antigen-157\% (47-197\%), fibrinogen$180 \mathrm{mg} / \mathrm{dl}(150-400 \mathrm{mg} / \mathrm{dl})$, and a normal urea clot lysis test. Platelet function test (PFT) (Chrono-Log aggregometer) showed severely impaired aggregation with $1 \mu \mathrm{l}$ collagen (19\%, normal $>50 \%$ ) (Fig. 1a). Aggregation with other agonists $(2.5 \mu \mathrm{l}$ and $5 \mu \mathrm{l}$ ADP, $5 \mu \mathrm{l}$ epinephrine, $1 \mu \mathrm{l}$ arachidonic acid, $2 \mu \mathrm{l}$ and $5 \mu \mathrm{l}$ ristocetin, and $2.5 \mu \mathrm{l}$ collagen) was normal. Treatment with Imatinib Mesylate (IM) $400 \mathrm{mg}$ once daily led to complete hematological remission (hemoglobin-11 g/l, white cell count- $8 \times 10^{9} / 1$, platelets- $250 \times 10^{9} / 1$, no immature myeloid cells, and absence of organomegaly), and a normal platelet aggregation with $1 \mu \mathrm{l}$ collagen after 2-weeks (Fig. 1b). Patient has no bleeding symptom, and is on regular follow-up. Platelet dysfunction has been reported in up to $80 \%$ of treatment-naïve CML patients, and could be due to either extreme leukocytosis or defective platelets produced by clonal megakaryocytes [1,2]. Correction of hemorrhagic diathesis with normalization of white cell counts supports the former view [1], and correction of PFT abnormalities with achievement of molecular response by tyrosine-kinase inhibitor (TKI) therapy strengthens the latter view. Moreover, TKI's have been associated with platelet-dysfunction due to inhibition of platelet-associated tyrosine kinase activity [3]. SDH is most often traumatic in origin. Although an association with hematological malignancy is known, SDH in CML is uncommon and is usually encountered in patients on TKI therapy. CML presenting with spontaneous acute SDH is exceedingly rare, and only one case has been described till date [4]. Reported 


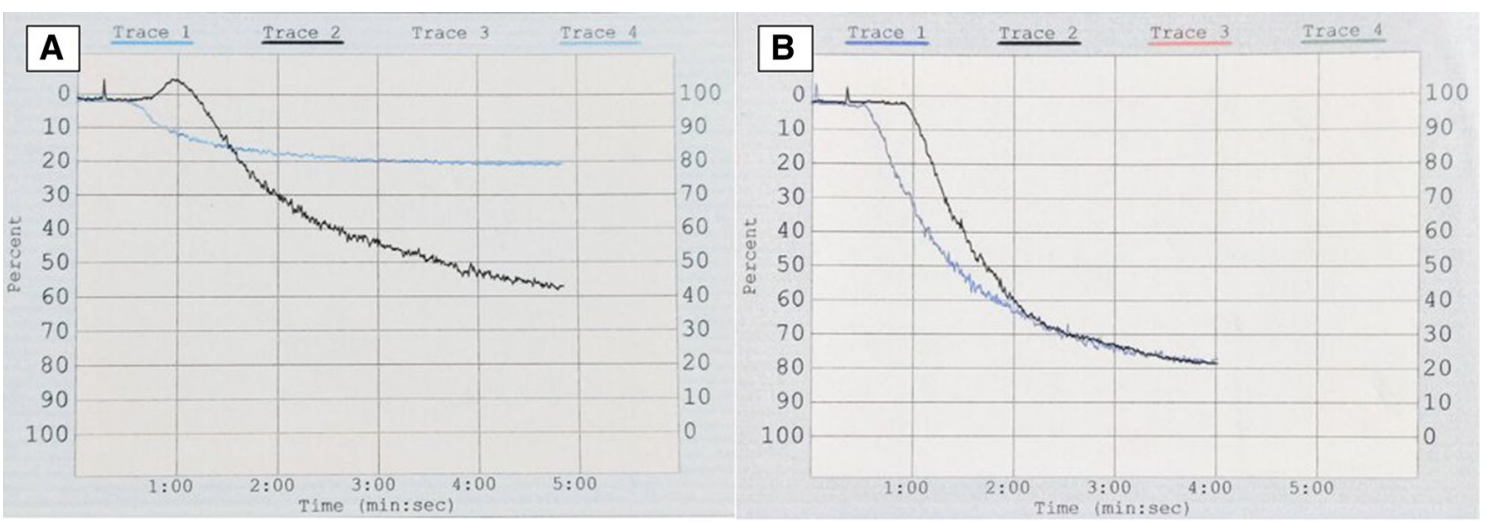

Fig. 1 Platelet aggregation trace of the patient (blue), and control (black) with $1 \mu$ l collagen showing- (a) impaired aggregation, and (b) normalization of the aggregation defect after treatment with Imatinib for 2-weeks (color figure online)

mechanisms of SDH in CML include- (a) IM-induced platelet dysfunction, and reduced $\alpha 2$-plasmin inhibitor, (b) dural metastasis, and (c) acquired von Willebrand disease [5]. Our patient had normal PT, APTT, TT, and normal levels of Factor VIII, IX, VWF, and XIII (urea clot lysis as a surrogate). In view of deranged PFT, plateletdysfunction was likely responsible for SDH in our case. We herein report an uncommon bleeding site in a treatment-naïve patient of CML secondary to platelet dysfunction, its correction with TKI therapy, and highlight that a detailed coagulation work-up including PFT is essential to ascertain the cause of bleeding in CML.

\section{Compliance with Ethical Standards}

Conflict of interest Authors have no conflicts of interests to declare.

Consent for publication The authors state that a written and informed consent was obtained from the patient prior to publication.

Ethical Statement The article has not been submitted elsewhere for consideration of publication. The article complies with the ethical standards by declaration of Helsinki.

\section{References}

1. Savage DG, Szydlo RM, Goldman JM (1997) Clinical features at diagnosis in 430 patients with chronic myeloid leukaemia seen at a referral centre over a 16-year period. Br J Haematol 96:111-116

2. Akay OM, Mutlu F, Gülbaş Z (2016) Platelet dysfunction in patients with chronic myeloid leukemia: does imatinib mesylate improve it? Turk J Haematol. 33:127-130

3. Ng AP, Servadei P, Tuckfield A, Friedhuber A, Grigg A (2009) Resolution of platelet function defects with imatinib therapy in a patient with chronic myeloid leukaemia in chronic phase. Blood Coagul Fibrinolysis 20:81-83

4. Abdulhamid MM, Li YM, Hall WA (2011) Spontaneous acute subdural hematoma as the initial manifestation of chronic myeloid leukemia. J Neurooncol 101:513-516

5. Jain A (2015) A rare case of chronic myeloid leukemia with acquired von Willebrand disease presenting as subdural hematoma. J Cancer Res Ther 11:1022

Publisher's Note Springer Nature remains neutral with regard to jurisdictional claims in published maps and institutional affiliations. 